\title{
COEDUCACIÓN EN EL AULA UNIVERSITARIA: DE LA TEORÍA COMO PRÁCTICA O DE CÓMO LO FAMILIAR SE VUELVE EXTRAÑO
}

\author{
Ana Iglesias Galdo \\ Universidade da Coruña
}

\begin{abstract}
RESUMEN: Reconociendo los principales avances en las políticas de igualdad entre mujeres y hombres, y reclamando las contribuciones de los Estudios de Mujeres, Feministas o de Género, se defiende el aula universitaria como espacio idóneo para hacer coeducación. Se propone teorizar, orientando al estudiantado en la práctica de la reflexión fundamentada, y en el descubrimiento de nuevos interrogantes que les permitan objetivar algunos de los elementos sociales que contribuyen a la generización de la cultura considerada común, y tomar así conciencia del grado de coerción y/o consentimiento de las relaciones sociales, en función de la variable género. Se defenderá la apropiación de este marco teórico crítico, en tanto conocimiento fundamental para el diseño y desarrollo de proyectos sociales realmente coeducativos, esto es, que aporten razones sobre la urgente necesidad de incorporar los saberes feministas a la práctica profesional y también a la vida cotidiana, en tanto garantía para reducir las diferentes brechas de género y poder así avanzar con firmeza hacia sociedades más justas.
\end{abstract}

PALABRAS CLAVE: Coeducación, feminismo, socialización cultural, injusticia de género.

\section{COEDUCATION IN THE UNIVERSITY CLASSROOM: FROM THEORY AS PRACTICE OR HOW THE FAMILIAR BECOMES STRANGE}

\footnotetext{
ABSTRACT: Recognising the main advances in gender equality policies and reclaiming the contributions of Women Studies, Feminists or of Gender, this paper presents the university classroom as an ideal place to co-educate. The metholology proposed is to theorize, guiding students in the practice of informed reflection and in the discovery of new questions that allow them to objectify some of the social elements that contribute to the genderization of the commom culture, in order to raise awareness of coercion and/or consent of the social relations depending on the gender variable. The article advocates
} 
for the appropriation of this theoretical framework as essential knowledge for designing and developing truly co-educational social proyects. Projects which give reasons and justify the urgent need of including feminist wisdom to both professional practice and everyday life as a guarantee to reduce the different gender barriers and so, be able to move firmly towards fairer societies.

KEYWORDS: Coeducation, feminism, cultural socialisation, gender's injustice.

Recibido: 29/03/2017

Aceptado: 01/09/2017

Correspondencia: Ana Iglesias Galdo, Facultad de Ciencias de la Educación, Campus Elviña, 15071 A Coruña. Email: anai@udc.es.

\section{A MOdo DE CONTEXTUALIZACIÓN}

Nuestros campus están formados por ciudadanos y esto significa que debemos preguntarnos cómo debe ser un buen ciudadano de hoy y qué debe saber. (Nussbaum, 2005, p. 27)

Reclamando las contribuciones de los Estudios de Mujeres, Feministas o de Género y asumiendo el compromiso colectivo de educar para la igualdad, proponemos el aula universitaria como espacio idóneo para hacer coeducación, reflexionando sobre la experiencia docente desarrollada en la materia "Género, Igualdad y Educación", en el Grado de Educación social ${ }^{1}$. Lejos de limitarnos a reproducir la guía docente (disponible en la web de la universidad y de acceso público), la principal aportación será dar cuenta de cómo la racionalidad en la que descansa la educación feminista, al comprometerse con una transformación profunda del actual orden social sexista, sobrepasa el carácter académico para tocar el personal, y exige para su desarrollo una serie de condicionantes que afectan a todos los elementos de la acción educativa.

Aun asumiendo que en ocasiones los modelos críticos universitarios dejan poco espacio para evidenciar las contradicciones, las incertidumbres, y la variabilidad contextual de las experiencias, entendemos éstos pueden ampliar las teorías y deben ser tenidos en cuenta para la construcción de nuevos saberes. Este punto de vista justifica que adoptemos el método de reflexión característico del enfoque crítico que

trata de educar a los profesionales promoviendo el conocimiento de sí mismos, con el fin de explorar la irracionalidad de sus creencias y prácticas de sentido común y localizar el origen de esta irracionalidad en el contexto institucionalizado y en las formas de vida social de las que tienen surgido. (Carr, 2002, p. 75)

1. La Facultad de Ciencias de la Educación de la UDC contemplaba en el plan de estudios de la Diplomatura de Educación social -desde su creación en el curso 1995-1996 hasta el 2.009-2010- la materia Género y Educación, ofertada como optativa. En el 2009-2010 se estrena el título de Grado en Educación social, ofertándose con carácter obligatorio en primer curso la asignatura Género, Igualdad y Educación. 
Bajo este planteamiento dialógico, llevo veinte años empezando cada curso de la misma manera: escuchando lo que piensa el alumnado sobre la (des)igualdad entre mujeres y hombres. En la introducción a cada núcleo temático busco sus opiniones espontáneas que, al no estar especialmente meditadas, arrojan luz sobre qué, cómo y dónde aprende esta juventud a construir su "sentido común" con respecto a esta temática².

Sus opiniones, los argumentos que construyen para avalar lo que piensan, son por veces dubitativos, contundentes e incluso apasionados, y constituyen una muestra de algunos supuestos de género arraigados en el imaginario social. Valgan como ejemplo los siguientes: creencia generalizada de que los sexismos actuales son residuales e incluso que se eliminarán a medida que la sociedad avance; percepción de las relaciones personales como neutras en cuanto al género; indignación ante los sexismos más vejatorios, pero cierto grado de complicidad ante aquellos más sutiles, sobre los que, aun rechazándolos, el nivel de crítica es débil; desconocimiento de las contribuciones del feminismo social y académico; escasa vinculación entre sexismo y opresión, cierta tendencia a explicar las desigualdades de género en términos de diversidad natural; dificultades para percibir la necesidad de políticas de acción positiva ligadas al reconocimiento y a la redistribución; uso y abuso del término "género" con escasa referencia a su dimensión estructural; opinión a priori sobre la mayoría de las temáticas, pero carencia de argumentación razonada y científica sobre éstas.

Escuchar este imaginario colectivo permite identificar "algunos de los hilos de color rosa tejidos en las redes educadoras, que son, las líneas y direcciones en las que podremos puntear el hilo violeta" (Amorós, 2005, p. 304); esto es, a través del diálogo entre diferentes saberes, proponiendo la teoría educativa crítica como práctica de aula, buscamos la producción de conocimiento significativo que permita ejercer los derechos y deberes propios de una ciudadanía democrática y transitar así hacia una mayor justicia social.

\section{Bases socioculturales del comportamiento: Sobre(el)peso de las RELACIONES DE GÉNERO EN LAS TRAYECTORIAS PERSONALES}

Las grandes declaraciones de los derechos humanos afirman que los seres humanos nacemos libres, iguales y no sometidos a servidumbres, pero nacemos también en el interior de sociedades jerarquizadas, herederas de una historia, caracterizadas por instituciones y organizaciones que tienen un peso determinado en nuestros modos de ser, de pensar, de actuar y de sentir, y que por tanto inciden en la formación de nuestra propia identidad. (Álvarez-Uría, 2009, p. 12)

En sus primeras intervenciones en el aula, el alumnado discrepa de las opiniones que justifican la desigualdad entre hombres y mujeres por razones de carácter biológico, pero también parece asumir que, por su carácter sociocultural, el cambio hacia una mayor igualdad será una cuestión solo de tiempo. Escogemos este asunto para empezar la materia, pues

2. Aun no pretendiendo afirmar que todo el alumnado comparta las opiniones seleccionadas como relevantes, creo que contribuyen a objetivar algunas de las raíces sexistas que siguen prendiendo especialmente allí donde no parece necesario reflexionar: en lo considerado como cultura/sentido común. 
algunos problemas biológicos son más fáciles de reparar que algunos problemas culturales, el origen social no está sistemáticamente relacionado con una mayor facilidad de cambio que el biológico, y algunas prácticas sociales pueden ser enormemente resistentes al cambio. (Nussbaum, 2012b, p. 353)

Aun reconociendo margen de libertad en las decisiones individuales, también cómo las diferentes culturas engloban diferentes mundos sociales -sin duda muy distantes entre sí-, destacamos el peso de las relaciones sociales en la formación de la llamada personalidad, asunto de especial importancia en el contexto actual, donde se impone la ficción de un "yo" totalmente autónomo, como bien explica la profesora Varela (2016): "La pretendida total autonomía del 'yo', promovida entre otros por todos aquellos que nos aseguran que todo está en la mente, oculta que nuestra singularidad es el resultado de interacciones y de redes sociales que regulan y dan sentido a nuestra existencia" (p. 15).

Siendo consciente de que el hecho de poder identificar el origen cultural de una práctica, no significa que su modificación esté libre de resistencias, resulta de gran relevancia reconocerlo, pues disipa la falsa creencia de "hecho inevitable" que rodea con tanta frecuencia la asunción de costumbres y tradiciones y, "al indicarnos contra qué factores estamos luchando nos da una mejor compresión de cómo podemos enfocar el tema de la reforma" (Nussbaum, 2012b, p. 354).

Para tomar conciencia del (sobre)peso, esto es, del grado de coacción/consentimiento que ejercen las relaciones de género en la configuración de las identidades, se hace necesario objetivar algunas elementos que contribuyen a generizar las culturas, al defender con Arnot (2009) que:

Una perspectiva de género nunca pretende ser exhaustiva ni tampoco única, pero sí apunta a ser productiva en su análisis de la importancia social de la educación. Las relaciones de género [...] son fundamentales para la definición del contrato social entre los individuos y el gobierno, y están profundamente implicadas en la distribución del poder y el control en la sociedad [...] y repercuten en el acceso diferencial de hombres y mujeres a los derechos y beneficios de la ciudadanía. (p. 19)

Aun reconociendo las debilidades del modelo de análisis de socialización diferencial, en los términos expresados por Connell y Pearse (2015: 97): es demasiado monolítico, supone que el aprendizaje de género es un asunto de adquisición de rasgos, muestra al aprendiz como pasivo y las agencias de socialización como activas, reconoce solo una dimensión del aprendizaje, etc.; entendemos pudiera ser rentable para la finalidad propuesta, al permitir enfocar directamente las relaciones sociales, como también tienen explicado: "Género es, ante todo, un asunto de relaciones sociales dentro de las cuales actúan los individuos y los grupos. [...] Es un escenario en el que nos enfrentamos a duras cuestiones prácticas sobre la justicia, la identidad y la supervivencia" (p. 11).

Resulta también relevante, y en un sentido similar, la reflexión de la profesora Cobo (2011) quien, compartiendo algunas de las debilidades de la definición, entiende que rechazar la categoría "género" sin adjetivos, y prescindir del supuesto de "las mujeres" como grupo oprimido, pueda debilitar el feminismo, al perder su sujeto colectivo (las mujeres). En sus palabras: "si tomamos como punto de partida 
los diferentes sistemas de dominio que fomentan el sexismo, pero sin tener en consideración la variable de dominio masculino como variable autónoma, entonces no damos cuenta suficiente de la existencia del patriarcado" (pp. 65-66).

Conviene pues, para analizar las relaciones de género, detallar con precisión los mandatos específicos que se supone deben cumplir las personas con (in)dependencia del binomio sexo-género, pues "estos mandatos pasan a formar parte de nuestra personalidad, de nuestros gustos y deseos, de nuestras capacidades y expectativas, y también de nuestros temores, pues la sociedad castiga duramente a las personas que no actúan de acuerdo con estos mandatos tan potentes" (Subirats, 2008, p. 315).

Con ese propósito, y bajo el interrogante planteado por Geneviève Fraisse (2016): “¿Dónde encontraríamos el poder que discrimina? ¿En las imágenes estereotipadas que fabrican atribuciones o en la organización social que construye y reproduce la jerarquía de clases a partir de la dualidad social?" (p. 88), en el trabajo de aula procedemos al estudio y análisis de una selección de fuentes bibliográficas que abordan estas temática ${ }^{3}$, organizando la información obtenida en dos apartados: En la primera parte, identificando los valores y/o mensajes socioculturales (im)prescindibles que, vinculados a prejuicios y estereotipos de género favorecen aprendizajes y valoraciones de forma diferenciada en función de esta variable; en la segunda, reflexionando sobre cuáles debieran ser eliminados y cuáles seleccionados como saberes básicos comunes para toda las personas. Tras este ejercicio, focalizamos el tan nombrado "éxito escolar de las chicas", al intuir que pudiera ser una ficción especialmente útil para quienes pretenden dar la igualdad por alcanzada. Veamos una síntesis del resultado de este proceso:

\section{VALORES (IM)PRESCINDIBLES}

Ser obediente Ser valiente. Es necesario aprender a dar y recibir afecto, ternura, desarrollar capacidad de observación e intuición, empatía, inteligencia global (solucionar los conflictos de la vida), solidaridad, interdependencia en el ámbito privado, pensar en el bienestar ajeno olvidando los propios intereses, a agradar, a quejarse (no a indignarse), a tener miedo a la soledad o a no encontrar pareja; agresividad para defender los propios intereses, asumir el espacio público como principal y en ocasiones único espacio de desarrollo, actividad y dinamismo, capacidad de decisión (relacionado con dominación), inteligencia, capacidad de deducción, capacidad de riesgo (como imprudencia/valentía), mostrar indiferencia ante el dolor, reprimir la empatía, competir, enfrentarse, mostrarse siempre dispuesto para seducir, ser mejor en lo que sea, firmeza, ostentación heterosexual...

Para profundizar un poco más en los estereotipos seleccionados, acudimos a dos de los informes sobre igualdad y percepción de la violencia de género: Jóvenes y género. El Estado de la cuestión. Un análisis a partir de fuentes secundarias (2015)

3. Artículos científicos: S. Acker (1995); C. Amorós (2005); G. Arenas (2006); P. Ballarín (2008); N. Blanco (2001) (ed.); A. Barbé i Serra, S. Carro y C. Vidal (2014); R. Cobo (2008) (ed.); A. Iglesias y P. Ballarín (2013); A. McRobble (2010); M.I. Menéndez (2006); A. de Miguel (2015); A. Miyares (2003); L. Posada (2012); M.D. Renau (ed.) (2012); A. Sánchez y A. Iglesias (2008); M. Subirats y A. Tomé (2007). 
y La evolución de la adolescencia española en la igualdad y la prevención de la violencia de género (2014), destacando lo siguiente:

- Compartiendo intereses similares, ellos están más interesados por el deporte y ellas por temas culturales y sociales.

- Las chicas dicen dar más importancia a la familia, a la salud y al tiempo libre, mientras que los jóvenes muestran más interés por ganar dinero y tener amigos.

- Los varones manifiestan algo más de interés que las mujeres por la política.

- Valores en las relaciones de pareja: Las cualidades masculinas más valoradas tienen que ver principalmente con el poder, la fuerza, la valentía, la firmeza, la autosuficiencia y la competitividad; se les presupone más proclives a la agresividad y a la violencia, y a aceptar con mayor naturalidad su sexualidad manifiesta. En las mujeres se valoran la sensibilidad, la capacidad de perdón y comprensión, la generosidad, la pasividad y dependencia afectiva; y se prefiere que non hagan manifiesta su sexualidad.

- Por encima de todo, la cualidad más valorada en las mujeres por los hombres es el atractivo físico.

Diferente/lgual valoración social. Aunque niñas y niños comparten muchos espacios, entre los seis y los ocho años, los niños empiezan a separarse de aquello que interpretan "como de niña" y, esta incipiente separación de los espacios, favorece que unas y otros aprendan unas reglas diferentes de las reglas comunes, con el agravante de que esta separación sexual aumenta con la edad. El hecho de que ellos no quieran parecerse a ellas, que sean más reacios a reconocerse en rasgos que vienen caracterizando a las niñas que a la inversa, es el resultado de un proceso de socialización donde los chicos aprenden que "ser chico" implica no solo ser distinto a ellas, sino ser mejor. Los chicos, con más frecuencia que las chicas, tienen más necesidad de identificar ciertas actividades como masculinas o femeninas y, no solo asumen cierta dominancia sobre las actividades que identifican como masculinas, sino que evitan aquellas identificadas como femeninas $y$, en ocasiones, en la adolescencia toman forma de dominio.

Ser siempre el mejor, el más... Se les enseña a los niños que son más importantes, esto es, una concepción empoderada de sí mismos; a darle gran importancia al dominio, a la jerarquía y al prestigio, a interpretar que han de hacer constantes listas de importancia: "quien es más... en lo que sea"; a no temer tener que llegar a la utilización de la fuerza, a tener miedo a no ser valientes, más aún, la poca disposición para solucionar algunos asuntos de un modo violento, puede ser considerado, desde el punto de vista social, un error en la formación del carácter.

Protagonismo/Llamadas de atención. La mayor o menor visibilidad infantil, se presenta fundamentalmente a través de dos tipos de conducta: bien en forma de ruido, alboroto, conflictos, o interrupciones; bien pidiendo permiso, obedeciendo las reglas, y prestando atención. Las primeras adquieren un protagonismo específico -al hacerse más visible para las personas adultas-, provocando una mayor interacción y por tanto una diferencia significativa de trato. Así, se les habla a los niños durante más tiempo y con mayor feedback, con más felicitaciones y apoyo, lo que hace que 
se animen a hacerse notar y, correlativamente, esta falta de atención en relación a las protagonizadas por las niñas, Ileva a que éstas tengan menos interés por ser protagonistas, por pretender ser lideresas; $y$, cuando lo son, a veces lo disimulan, como si estuviera mal visto significarse.

Además, esta diferencia de trato tiene otros efectos no menos sexistas: por un lado, considerar como principal referente de protagonismo el adoptado por los niños, y, correlativamente, el practicado mayoritariamente por las niñas que, si bien no llama la atención, es considerado como "demasiado paciente/tranquilo". Por otro, destaca una mayor permisividad respecto de las conductas disruptivas cuando son protagonizadas por niños.

Formas de demostrar afecto y amistad. A través de contactos corporales suaves: besos, abrazos, susurros, cogerse de la mano o de gancho; pero también son consideradas como tales ciertos tipos de golpes, peleas y burlas en tanto formatos suaves de aprender a defenderse, hacerse fuertes y diferenciarse.

\section{ÉXITO ESCOLAR/SOCIAL}

Tienen mejor rendimiento, sacan mejores notas, abandonan menos, se esfuerzan y estudian más y durante más tiempo. No solo los resultados finales, sino toda la estancia en la escuela es mejor para las chicas que para los chicos: les gusta más estudiar, viven la trayectoria escolar ligada a la promoción personal, profesional y cultural; la aceptan como garantía de éxito personal que rompe definitivamente con el rol tradicional y prepara el camino para una autonomía personal y económica en la vida adulta. Los chicos se distraen más, acatan menos las normas, se desaniman con más facilidad, tienen peor rendimiento y muestran más indiferencia ante el aprendizaje académico. Los datos recogidos en el último informe sobre Las cifras de la educación en España. Curso 2014-2015, muestran la evidencia de esta brecha educativa:

- Los porcentajes de promoción y de titulación de las mujeres son mejores que los de los hombres en los diferentes niveles educativos. Se destaca que la tasa bruta de Graduados en ESO es de $82,2 \%$ para las mujeres y de $71,7 \%$ para los hombres.

- El abandono temprano de la educación-formación en el año 2015 es del 24\% para los hombres y del 15,8\% para las mujeres.

- El indicador de nivel de formación de educación superior se sitúa en 47,1\% para las mujeres y $34,8 \%$ para los hombres.

- Alumnado con necesidad específica de apoyo educativo: 61,9\% de hombres y $38,1 \%$ de mujeres.

- Bachillerato: Las chicas repiten en menor porcentaje y promocionan en mayor porcentaje en ambos cursos. Superan la prueba de acceso más mujeres: $55.9 \%$.

- A igual nivel educativo alcanzado, la tasa de actividad y de empleo es mayor en los hombres y la tasa de paro es mayor en las mujeres.

- Programas de Cualificación Profesional Inicial por familia profesional: Con más de un 50\%, las mujeres escogen Imagen Personal (81.3); Sanidad (57), Comer- 
cio y Marketing (55.1) y Textil, Confección y Piel (52.3); con menos de un 15\%, escogen Fabricación mecánica (5.7), Transportes y Mantenimiento de vehículos (6.7), Marítimo Pesquero(12,1) y Edificación y Obra Civil (12.7).

- Distribución porcentual del alumnado de Bachillerato según modalidad: Las chicas escogen Artes (6.6), Humanidades y Ciencias Sociales (53.9), Ciencias y Tecnologías (38.9) y no distribuido por modalidad (0.7).

Para ampliar la información, consultamos el último informe sobre Mujeres y hombres en España (2017), donde vemos algunas de las brechas de género producidas por las condiciones y características de la oferta de trabajo actuales: salarios, puestos de responsabilidad, reparto de cargas familiares, participación en el trabajo no remunerado, repercusión en el empleo de la existencia de hijos, etc.

Las cifras reflejan algunos de los efectos del androcentrismo cultural y de los sexismos enraizados en las diferentes estructuras y formas de organización educativa, pues aun siendo el rendimiento académico de las chicas superior, tienen repercusiones discriminatorias en sus trayectorias adultas. Así, son ellos quienes adquieren mayores puestos de responsabilidad, tienen más iniciativas profesionales y, en mayor medida, ejercen las profesiones para las que se formaron. Como apunta M. Subirats (2016): "está claro que este éxito académico no tiene los mismos rendimientos para las mujeres que para los hombres ni en el terreno económico ni en el acceso al poder"; son pues triunfantes perdedoras, en expresión de G. Arenas (2006).

En la misma dirección crítica sobre la representación de las niñas y las mujeres jóvenes como portadoras de los valores de la nueva meritocracia, los resultados del trabajo realizado por Iglesias y Ballarín (2013), inducen a pensar que tras el discurso del "éxito escolar de las chicas" se alimenta una importante y arraigada preocupación de los que conciben -mucho más de los que lo nombran- que el mejor servicio de las mujeres a la sociedad (maternidad, cuidados familiares y trabajo doméstico en general) se puede ver minado por su éxito profesional. Cuestión que recobra valor cuando la crisis económica requiere fuertes soportes familiares para gestionar la precariedad.

Otras investigaciones recientes apuntan que estamos asistiendo a una reformulación de las desigualdades de género que, dirigiéndose especialmente a las mujeres jóvenes, constituye una potente apuesta por desintegrar los triunfos del feminismo. McRobble (2010) tiene explicado esta nueva estrategia o dispositivo, consistente en reafirmar nuevos estilos de feminidad normativa "retradicionalizados", acuñando la expresión mascarada postfeminista. Se trataría de una narrativa que, hablando menos de lo que las mujeres jóvenes no pueden hacer y más acerca de lo que pueden hacer (cargando sus significados hacia la capacidad, el éxito, los logros, el disfrute, el derecho, la movilidad social y la participación), y adaptando el discurso como si dependiera solo de una elección personal, se dirigen a ellas como si ya tuvieran "conciencia de género", y las invitan a reconocerse como sujetos privilegiados del cambio social.

Sobre esta recolonización cultural, también resultan esclarecedoras las investigaciones que señalan a los medios de comunicación de masas como una de las vías favoritas para su difusión. Como explica De Miguel (2015), perviven viejos estereo- 
tipos que, ligados al "rosa y el azul", ofrecen un consumo diferenciado para chicas y chicos, de manera que cada día comparten menos productos culturales, menos símbolos que, como sucede con las novelas, películas y canciones, acaban dotando de sentido a la vida: "Para ellas el culto a la imagen personal, al cotilleo y al amor romántico. Para ellos la tríada fútbol-motor-pornografía [...]. El amor romántico, la violencia y la prostitución como factores de socialización diferencial" (pp. 37-38).

Tras el estudio y debate de los diferentes textos, el alumnado parece tomar más conciencia de la complejidad e injusticia de esta temática, y objetivar con mayor precisión el peso de las relaciones sociales en las biografías personales. En todo caso, parece persistir cierta dificultad para conceptualizar las relaciones de género como relaciones de poder, esto es, para vincular el patriarcado con un sistema de dominación, lo que nos lleva a proponer como segundo tema de estudio, los micromachismos.

\title{
Micromachismos QUe infeCtan la CULtURA COMÚN Y ALIMENTAN LA VIOLENCIA DE GÉNERO
}

\begin{abstract}
Disculpen las molestias, nos están asesinando. (Grandes, 2017)
Nada debiera impedirnos enjuiciar aquellas prácticas culturales que vulneren los derechos humanos, impliquen trato discriminatorio para las mujeres, o erosionen la igualdad. (Cobo, 2011, p. 25)
\end{abstract}

Para seguir acercándonos a la opresión del patriarcado, empezamos preguntando al alumnado lo que entienden por micromachismos (mM). Sus respuestas recogen confusiones importantes tanto con esta expresión, como con otra que emerge con fuerza durante esta dinámica: la violencia de género ${ }^{4}$.

"Pequeñas tiranías" "Terrorismo íntimo" "Violencia blanda" "Violencia suave" "Violencia de muy baja intensidad" "Machismo invisible" "Sexismo benévolo": bajo estas y otras denominaciones, en diversos estudios de la vida cotidiana, se nombra lo que Luis Bonino (2004) acuñó con el término de micromachismos (mM)

Los pequeños, casi imperceptibles controles y abusos de poder casi-normalizados que los varones ejecutan permanentemente. Son hábiles artes de dominio, maniobras y estrategias que, sin ser muy notables, restringen y violentan insidiosa y reiteradamente el poder personal, la autonomía y el equilibrio psíquico de las mujeres, atentando, además, contra la democratización de las relaciones. Dada su invisibilidad se ejercen generalmente con total impunidad. (p. 3)

Como el psicoterapeuta tiene explicado, se trata de un neologismo compuesto a partir de los términos "micro" y "machismo". Con el término machismo se llama la atención sobre manifestaciones cotidianas del sexismo subyacente en la estructura social, a través de comportamientos de desvalorización hacia las mujeres que, como también tiene reflexionado Victoria Sau (2000), en ciertos casos son considerados incluso normales, pasando inadvertidos tanto para las mujeres que los sufren como para los varones que los ponen en práctica.

4. Bibliografía básica para analizar esta temática: L. Bonino (2004); M. Castells y M. Subirats (2007); R. Cobo (2011); A. Iglesias (2015); M. Lorente (2009); M. Miedzian (1995); L. Nuño (2013); R. Osborne (2009); R. Rodríguez (2015); T. San Segundo (2016); M. Subirats (2008); N. Varela (2017). 
En cuanto al término micro, se pretende destacar la práctica de dominación masculina también en el orden de lo capilar, enfatizando así su carácter imperceptible. La referencia al tamaño pequeño ("micro") viene derivada de su carácter de normalidad social, pues al tratarse de un repertorio conductual cómodamente instalado en la vida cotidiana, frecuentemente es asumido como la única manera de ver e interpretar el mundo, esto es, se convierte en el sentido común de la mayoría social de la ciudadanía, al no parecer necesario someterlo a crítica.

Es éste un término inspirado en las investigaciones que, sobre los poderes, realizó Michel Foucault (1979), quien propone analizarlos muy minuciosamente, hasta llegar a su parte microscópica: "Se trata de coger el poder en sus extremidades, en sus confines últimos, allí donde se vuelve capilar, de asirlo en sus formas e instituciones más regionales, más locales" (p. 142).

Tras este análisis, mientras seguimos trabajando los textos teóricos, sugiero al estudiantado que piensen sobre tres tipos de micromachismos que hayan sufrido en algún momento de su vida. Hacemos un breve repaso y, se sorprenden de aquellos que, como bien explica la profesora Ana de Miguel (2015)

aluden a cómo los hombres consiguen evitar participar en lo doméstico y abusar de la capacidad femenina del cuidado. Cómo logran extraer de la relación un uso abusivo del espacio físico y del tiempo para sí. Con este fin, los hombres practican la resistencia pasiva, logran imponer la distancia y que les dejen en paz. (p. 337)

El debate sobre este asunto aporta una nueva dimensión a lo trabajado previamente sobre los mensajes socioculturales -también coactivos y también a menudo imperceptibles e (in)conscientes-; y a medida que su nivel de crítica aumenta, consiguen ver con claridad la fuerza bruta de la estructura que los mantiene. Es en este momento cuando recurrimos a la reflexión de Kate Millet (2017):

No estamos acostumbrados a asociar el patriarcado con la fuerza. Su sistema socializador es tan perfecto, la aceptación general de sus valores tan firmes y su historia en la sociedad humana tan larga y universal, que apenas necesita el respaldo de la violencia. Por lo común, sus brutalidades pasadas nos parecen exóticas o 'primitivas' y las actuales extravíos individuales, patológicos o excepcionales, que carecen de significado colectivo. Y, sin embargo, al igual que otras ideologías dominantes, como el racismo y el colonialismo, la sociedad patriarcal ejercería un control insuficiente, e incluso ineficaz, de no contar con el apoyo de la fuerza, que no solo constituye una medida de excepcionalidad, sino también un instrumento de intimidación constante. (p. 100)

En los comentarios a este texto emerge con fuerza un trío conceptual: culturaviolencia-identidades de género y, para situarnos, recogemos algunos aspectos sobre la evolución de las relaciones de pareja en adolescentes, reflejadas en dos estudios: Jóvenes y género. El Estado de la cuestión. Un análisis a partir de fuentes secundarias (2015) y La evolución de la adolescencia española en la igualdad y la prevención de la violencia de género (2014):

- Se mantiene la justificación de la violencia como resolución de conflictos, siendo el porcentaje de chicos triple que el de chicas.

- Se produce un incremento del mensaje de personas adultas de que "los celos son una expresión del amor". El porcentaje de chicas que han escuchado este 
consejo a menudo o muchas veces pasa del $29,3 \%$ al $35,8 \%$, y el de chicos del $29,3 \%$ al $36,8 \%$, lo que puede indicar un descenso en la conciencia de que suelen formar parte del control abusivo. Además, si se tienen en cuenta a quienes afirman haberlo escuchado algunas veces, se observa que casi tres de cada cuatro adolescentes (73,3\%), independientemente de su sexo, han escuchado este consejo de una persona adulta en alguna ocasión.

- El 81,5\% de los chicos y el 71,6\% de las chicas han escuchado en alguna ocasión el consejo "si alguien te pega, pégale tú", por parte de una persona adulta.

- Se produce un incremento de las adolescentes que reconocen que han sufrido situaciones de maltrato por parte de su pareja:

- El control abusivo (control de con quién habla, lo qué dice o a dónde va) es el más frecuente: el 28,8\% reconocen haberlo sufrido.

- La novedad es que ahora se ejerce el control a través del móvil, el 25,1\% de las chicas reconocen que lo han sufrido.

Ante este marco, optamos por problematizar el constructo de masculinidad hegemónica, dado que una de las finalidades de la coeducación, consiste en desactivar los códigos de género y: "competir es la gran palabra de la masculinidad de nuestro tiempo, una palabra que ha pasado del deporte a la economía y de ella a invadir el conjunto de la sociedad. Competir, es la versión actual de pelear" (Subirats, 2007, p. 98). Además, siguiendo a la socióloga, resulta interesante no perder de vista que:

Si hay una pauta que tradicionalmente ha sido definitoria del género masculino, una actitud que, bajo diversas formas, encontramos como exigencia para los varones en todas las culturas, y que además es considerada como diferenciadora de lo que se espera de las mujeres, es la valentía. (Subirats, 2008, p. 315)

La expresión mM como nutriente de la violencia de género empieza a dominar en los debates de todos los grupos de trabajo. Descubren que la expresión "violencia de género"(a pesar de no iluminar toda la realidad que pretende), tiene que ver con lo que el movimiento feminista viene nombrando durante décadas bajo diferentes expresiones: "violencia sexista", "violencia patriarcal", "violencia machista" o, simplemente, "violencia contra las mujeres"; y ubican como núcleo significativo, lo que de social y estructural tiene este tipo de conductas, pues más allá de las diferencias biológicas entre las personas, las desigualdades de derechos entre hombres y mujeres, obedecen a una diferente posición estructural que ocupan en la sociedad, y a las consecuencias psíquicas que esa desigualdad comporta (Izquierdo, 2006).

Apelamos también a su definición en la legislación actual5: "todo acto de violencia física y psicológica, incluidas las agresiones a la libertad sexual, las amenazas, las coacciones o la privación arbitraria de libertad", reflexionamos sobre su objetivo: "Actuar contra la violencia que, como manifestación de la discriminación, la situación de desigualdad y las relaciones de poder de los hombres sobre las mujeres, se ejerce sobre éstas por parte de quienes sean o tengan sido los cónyuges o de quien esté o tenga estado ligado a ellas por relaciones similares o de afectividad, aún sin

5. Ley orgánica 1/2004, de 28 de diciembre, de medidas de protección integral contra la violencia de género (LOVG, 2004). 
convivencia"; detectamos algunas insuficiencias y buscamos algunas propuestas para su mejora. Como reflexión final optamos por querer quedarnos sin aliento:

La violencia de género es la violación de los derechos humanos más extendida en el mundo. Cada año, entre millón y medio y tres millones de mujeres y niñas pierden la vida como consecuencia de la misma. Naciones Unidas estima que siete de cada diez mujeres sufrirá golpes, violaciones, abusos o mutilaciones a lo largo de su experiencia biográfica. Y, entre aquellas con edades comprendidas entre los 15 y los 44 años, la violencia de género causa más muertes y discapacidades que el cáncer, la malaria, los accidentes de tráfico y los conflictos armados juntos.

Tomándonos muy en serio este déficit democrático, y bajo el propósito de poder substituir la complicidad por la tolerancia cero ante esta injusticia, emerge con fuerza la defensa de un modelo de Educación social crítico -sin este componente la educación no será transformadora-, y la necesidad de una mayor implicación de todas las instituciones para garantizar la formación de toda la ciudadanía en coeducación.

\title{
Sociedades COEDUCADOras para DeSMONTAR la ACTUAL CULTURA DEL SIMULACRO
}

\begin{abstract}
Nuestra propuesta se dirige a la formación universitaria que debe ser la que se ocupe, en primera instancia, de garantizar los conocimientos, destrezas y competencias esenciales para el desarrollo de la igualdad entre hombres y mujeres en cualquier ámbito de actuación y, en especial, de la formación básica obligatoria para toda la ciudadanía (Ballarín, 2008, p. 183)
\end{abstract}

Bajo el objetivo de revisar y actualizar agenda, y remover los nuevos obstáculos educativos que están impidiendo la igualdad real, entendemos que las instituciones educativas -también las universitarias-, deben incorporar a sus estudios los saberes producidos desde los feminismos. Coincidimos así con la profesora Ballarín y también con la filósofa Martha Nussbaum (2005), al entender que la educación superior debe tener por meta crear una comunidad crítica, que busque la verdad más allá das barreras de clase, género y nacionalidad, que respete la diversidad y la humanidad de otros; y al proponer que cada universidad debería considerar el modo de incorporar estas cuestiones y perspectivas a cursos básicos obligatorios, de manera que el alumnado tenga la experiencia de ver a través del 'prisma de género', al considerar que produce una mejor ciudadanía, una ciudadanía más capaz de revisar temas complejos sobre las mujeres que, con seguridad, tendrán que manejar en sus vidas, tanto públicas como privadas; y que estas discusiones son valiosas para todo el estudiantado, no sólo para las mujeres.

Una nueva vía de intervención educativa para desafiar los mecanismos de sexualización en la vida cotidiana, en tanto requisito de un proyecto político que posibilite a todas las personas "ser" con independencia de sexo-género, es la de poner a disposición de toda la ciudadanía contenidos culturales relevantes que contribuyan a provocar cambios en los niveles de conciencia de las personas. Formular la construcción de la ciudadanía desde este marco, entender la coeducación como proyecto social 
colectivo que pone en práctica la igualdad exige, por un lado, nuevas políticas -además del cumplimiento riguroso de las actuales-y, por otro, un mayor compromiso de la sociedad civil en su desarrollo, exigiendo el aprendizaje de la igualdad:

para hacer y comprender algo hay que estudiarlo y aprenderlo. No basta con saber que existe, que es conveniente, correcto y justo. Hay que aprender y practicar, tomando afecto en el proceso. [...] La igualdad hay que aprenderla y practicarla continuamente, porque no viene incrustada en las culturas que nos precedieron, porque no se muestra por milagro ni se transmite por esporas. (Simón, 2015, p. 228)

Pero ¿Cómo se aprende a tener conciencia de género? ¿Qué saberes son imprescindibles? ¿Quiénes enseñan la igualdad? ¿Qué familiares la transmiten en los actos de su vida cotidiana? ¿Qué instituciones? ¿Qué materias obligatorias aseguran su aprendizaje como bien básico cultural para toda la ciudadanía, desde la Educación Infantil a la Universitaria? ¿En qué libros de texto? ¿En qué redes sociales? ¿En qué espacios, programas o textos de uso informal se aprende: revistas, prensa, deportes, fiestas -los diferentes actos de recogida de premios son un ejemplo de lo contrario-, libros, calles, web, juegos, publicidad...?. Buscamos nuevos textos científicos para practicar la reflexividad ${ }^{6}$.

Con las lecturas emerge un interrogante especialmente pertinente para el tema que nos ocupa: ¿Cuenta todo el profesorado con formación en estudios de género? Acudimos a los resultados de la Investigación Evaluación de la incidencia de los saberes de las mujeres, feministas y de género en la docencia universitaria, que tenía como objetivo indagar en las creencias y prejuicios arraigados en el ámbito académico y que impiden el reconocimiento de los conocimientos construidos desde el feminismo. Resulta especialmente iluminador, pues desvela algunos de los obstáculos que impiden seguir avanzando al ritmo deseado y, en este sentido, pueden ser leídos también como retos pendientes. Reproducimos de forma sintetizada dos de los resultados recogidos por la investigadora principal, la profesora Ballarín (2013):

- Desconocimiento y no reconocimiento de la producción científica sobre las mujeres. La posición mayoritaria del profesorado entrevistado muestra un desconocimiento notable de la producción científica y al no reconocer, por no conocer, un saber específico, entiende así que no se necesita ninguna formación específica para intervenir en la docencia sobre temas de igualdad y no discriminación. En consecuencia, se rechazan materias específicas, el feminismo se llega a considerar radicalismo o algo del pasado y, la denominación de Género para referirse a estos Estudios genera confusión. Desde esta concepción de la igualdad como un hecho, reaparece con fuerza el concepto de "persona", en el que se disuelven y ocultan las diferencias de género, y se enfatiza que solo hace falta una "actitud" adecuada.

- Conciencia sin ciencia. La inclusión o no de contenidos explicativos sobre las cuestiones que nos ocupan se hace depender del interés que personalmente despiertan. De este modo, lo que denominan "conciencia", en sus discursos, se relaciona más con la "sensibilidad" que con la "razón". Así la "conciencia"

6. Añadimos a los primeros textos trabajados las reflexiones vertidas en los siguientes: M. Arnot (2009); P. Ballarín (2008, 2013, 2015); C. Lomas (2004); C. Nigozi (2017); C. Rodríguez (2011); M. Sánchez (2009); R. Savin-Willians (2009); E. Simón (2015); M. Subirats (2016); A. Tomé y X. Rambla (2001); A. Valcárcel (2009). 
constituye una especie de sensibilización, producto de la experiencia empírica, que se produce de forma espontánea y en la que la ciencia no tiene cabida. Además, la consideración de temática "social", hace que una parte importante del profesorado universitario se ocupe de la temática en muchos casos por demanda del alumnado, siendo esta forma incidental de hablar de cuestiones "concienciadoras", "de actitud", a lo que denomina el profesorado "transversalidad".

Para promover que varones y mujeres sean moral y políticamente iguales, la universidad, en su función educadora, ha de ser más exigente en el desarrollo de las capacidades, en el sentido propuesto por Nussbaum (2012a), que las conceptualiza así:

Capacidad significa 'oportunidad de seleccionar. La noción de libertad de elección está, pues, inscrita en el concepto mismo de capacidad [...]. Las preguntas que debemos hacernos son: ¿Qué son las personas realmente capaces de hacer y de ser? ¿Cuáles son las oportunidades reales que la sociedad les ha dado para actuar y para elegir? (p. 51, p. 80)

Preguntas de este calado son las que pueden ayudar a desvelar la actual cultura del simulacro "en la que el patriarcado disimula el poder que tiene y simula que la igualdad entre mujeres y hombres es un objetivo ya conquistado [...]. Para todo ello necesita perpetradores, pero también son necesarias las complicidades y el silencio que alimenta la impunidad" (Varela, 2017, p. 122).

\section{La CONClusión SE VUelVe EVIDENTE: QueRemos más FeMINISMO}

Y, para ir hacia la conclusión, percibo que hay todavía un grave déficit de voluntad común. (Valcárcel, 2009, p. 331)

Durante el transcurso de la materia, más allá de los temas seleccionados para esta reflexión, el alumnado muestra una fuerte motivación hacia la acción, diríase que es especialmente sensible a las injusticias -también a las derivadas del sistema sexogénero-, y en menor medida hacia la teoría educativa que, con cierta frecuencia, perciben como conocimiento "académico" alejado de la práctica profesional. Los textos seleccionados contribuyen a problematizar algunos de supuestos implícitos en el binomio teoría-práctica. Como nos explica Acker (1995): "las estructuras teóricas feministas hablan, sobre todo, acerca de la cuestión de la subordinación de las mujeres a los hombres: cómo surgió, cómo y por qué se perpetúa, cómo podría cambiarse, y (a veces) cómo sería la vida sin ella" (p. 64). En definitiva, buscamos que se apasionen con el conocimiento y asuman el reto de entender la realidad en su dimensión más compleja, pues introducir la perspectiva de género en la ciudadanía "exige una comprensión más profunda de las relaciones patriarcales y de género en la sociedad y de la manera en que éstas se interconectan con el gobierno, la democracia y el papel del Estado" (Arnot, 2009, p. 38).

Bajo este prisma, en el planteamiento y desarrollo de esta materia pretendemos comprometernos -hasta donde nos sea posible- con los siguientes enunciados de la educación feminista (Crabtree, Sapp y Licona, 2009, pp. 5-6):

- Transformar el pensamiento en acción. 
- Visibilizar las formas en que la producción tradicional de conocimiento y el conocimiento recibido sirven a intereses particulares y configuraciones sociales de poder mediante la exclusión sistemática o la opresión de clases particulares de personas.

- Poner en primer plano la historia y la fuerza del sexismo y la heteronormatividad en la sociedad.

- Reconocer diferentes formas de conocimiento personal, comunal y subjetivo.

- Usar una ética de la atención.

- Ayudar al estudiantado a hacer conexiones entre los estudios y sus vidas. Buscar no solo mejorar el aprendizaje conceptual, sino también promover la concienciación, el crecimiento personal y la responsabilidad social.

- Hacer un análisis crítico de la educación.

- Desarrollar relaciones no jerárquicas y asumir la reflexividad sobre las relaciones de poder.

- Desarrollar estrategias de enseñanza que resistan a la reinscripción de las nociones culturales dominantes sobre género, raza, sexualidad y clase y, deliberadamente, problematicen términos y construcciones esencialistas que históricamente marginalizaron y oprimieron la experiencia humana de ciertos individuos y grupos.

- Adoptar esta forma de vivir profesional y personalmente.

Lejos de ser tarea fácil, optar por reconocer y aprender los saberes producidos por los Estudios de Género requiere, además del obvio esfuerzo académico, cierta dosis de valentía, pues contar con mayor o menor capacidad de crítica implica (trans) formación personal ${ }^{7}$. Las voces del alumnado resultan imprescindibles para seguir avanzando y, por veces incómodas, parecieran increpar con cierto desaire, como si en algunos asuntos les molestara el conocimiento que les aportan los artículos seleccionados, e incluso me hicieran única responsable del mismo. Sin duda, estos saberes contribuyen a ampliar las posibilidades para decidir qué modelos educativos entienden serán más justos, pero también para preguntarse "quienes queremos ser".

Tras el estudio de estos primeros temas, acabamos compartiendo indignación también cierto cansancio-, al comprobar cómo las injusticias de género forman parte de la vida diaria, de la cultura común y, como tales son, en mayor o menor grado, asumidas por las políticas actuales y transmitidas como saberes legítimos por las principales instituciones socializadoras y educativas -con independencia del grado de intencionalidad de quien las transmite, y también del de (in)consciencia de quien las aprende-. A modo de síntesis, valgan como ejemplo las siguientes: Tener más dificultades para el reconocimiento de autoridad y prestigio, falta de apoyo presupuestario a las políticas de igualdad, exaltación de la maternidad, violencia machista, prostitución, falta de derechos sexuales y reproductivos, sufrir la ginofobia del mercado

7. Pudiera parecer poco riguroso apelar a lo personal, pero "Lo personal es político, valida la naturaleza política de las experiencias y voces individuales de las mujeres y actúa como un recordatorio de que la teoría y la investigación intelectual tienen una responsabilidad para con la sociedad" (Crabtree, R, Sapp, D. y Licona, A., 2009, p. 6). 
(cobrar menos por el mismo trabajo, más trabajo a tiempo parcial, menos posibilidades de empleo, peores empleos y sufrir techo de cristal), disponer de menos tiempo para el ocio, sufrir cotidianamente los micromachismos, ninguneo institucional a las demandas, realizar más tareas domésticas y de cuidado, mayor probabilidad de pobreza, aprender un estatus de "segunda", deber de agradar...

Este listado de agravios busca incomodarnos y, desde esta angustiosa sensación, interpelar a quienes, cuando en fechas cercanas al 8 de marzo o al 25 de diciembre se les pregunta ¿Se considera usted feminista?, año tras año contestan: Depende, depende de lo que se entienda por feminismo, o No me gustan las etiquetas. Yo prefiero hablar de personas y no de géneros. Volvamos de nuevo, para explicar bien los motivos para serlo, a Amelia Valcárcel (2009):

Tres siglos de teoría y práctica avalan el feminismo: esa tradición política de la modernidad, igualitaria y democrática, que mantiene que ningún individuo de la especie humana debe ser excluido de cualquier bien y de ningún derecho a causa de su sexo (...). Feminismo es pensar normativamente como si el sexo no existiera o no fuera relevante. (...) pero se necesita porque sí existe, sí es normativo y además siempre es parcial y siempre de la misma manera: en contra de las oportunidades de las mujeres y sus derechos. (pp. 214-215)

Y para quienes insisten en preguntar ¿Pero qué más quieren? ¿Qué quieren las mujeres? La respuesta es evidente: Queremos más feminismo.

\section{REFERENCIAS BIBLIOGRÁFICAS}

Acker, S. (1995). Género y Educación: Reflexiones sociológicas sobre mujeres, enseñanza y feminismo. Madrid: Narcea.

Álvarez-Uría, F. (2009). Sociología de las instituciones: Bases sociales y culturales de la conducta. Madrid: Morata.

Amorós, C. (2005). Globalización y orden de género. En C. Amorós y A. De Miguel (Ed.), Teoría feminista: de la Ilustración a la globalización. De los debates sobre el género al multiculturalismo (pp.301-332). Madrid: Minerva.

Arenas, G. (2006). Triunfantes perdedoras. Barcelona: Graó.

Arnot, M. (2009). Coeducando para una ciudadanía en igualdad: Compromiso con las agendas globales y nacionales. Madrid: Morata.

Ballarín, P. (2008). Retos de la escuela democrática. En R. Cobo (Ed.), Educar en la ciudadanía: Perspectivas feministas (pp. 151-186). Madrid: Catarata.

Ballarín, P. (2013). Docencia universitaria y no reconocimiento de la producción científica sobre las mujeres. Cuestiones de género: de la igualdad y la diferencia, 8, 89-106.

Ballarín, P. (2015). Los códigos de género en la universidad. Revista Iberoamericana de educación, 68, 19-38.

Barbé i Serra, A., Carro, S. y Vidal, C. (2014). La construcción de las identidades de género: Actividades para trabajar con jóvenes y adolescentes. Madrid: Catarata.

Blanco, N. (Ed.) (2001). Educar en femenino y en masculino. Madrid: Akal.

Bonino, L. (2004). Los micromachismos. Revista Cibeles, 2. 
Carr, W. (2002). Una teoría para la educación. Hacia una investigación educativa crítica. Madrid: Morata. $3^{\text {a }}$ ed.

Castells, M. y Subirats, M. (2007). Mujeres y hombres. Madrid: Alianza.

Cobo, R. (Ed.) (2008). Educar en la ciudadanía. Perspectivas feministas. Madrid: Catarata.

Cobo, R. (2011). Hacia una nueva política sexual. Las mujeres ante la reacción patriarcal. Madrid: Catarata.

Connell, R. y Pearse, R. (2015). Gender: In World Perspective. London: Polity Press. $3^{\mathrm{a}} \mathrm{ed}$.

Crabtree, R. D., Saap, D. A. y Licona, A. C. (Ed.) (2009). Feminist Pedagogy. Looking back to move forward. Baltimore, MD: The Johns Hopkins University Press.

De Miguel, A. (2015). Neoliberalismo sexual: El mito de la libre elección. Madrid: Cátedra. Colección Feminismos.

Foucault, M. (1979). Microfísica del poder. Madrid: La Piqueta.

Fraisse, G. (2016). Los excesos del género. Concepto, imagen, desnudez. Madrid: Cátedra. Colección Feminismos.

Grandes, A. (2017): Nos están asesinando. El país semanal, 6 de marzo 2017.

Iglesias, A. y Ballarín, P. (2013). El mito del 'éxito' escolar de las chicas. Revista Sarmiento, Anuario Galego de Historia da Educación, 17, 67-82.

Iglesias, A. (2015). Prólogo. En CEESG, Fiadeiras, Machismos: de micro nada (pp.1012). A Coruña: Embora.

Izquierdo, M. J. (2006). As ordes da violencia: especie, sexo e xénero. En A. Sánchez (Ed.), Políticas públicas de igualdade. Perspectiva de xénero (pp.147-179). Santiago de Compostela: Laiovento.

Lomas, C. (Comp.) (2004). Los chicos también Iloran. Identidades masculinas, igualdad entre los sexos y coeducación. Barcelona: Paidós.

Lorente, M. (2009). Los nuevos hombres nuevos: Ios miedos de siempre en tiempos de igualdad. Barcelona: Destino.

McRobble, A. (2010). ¿Las chicas arriba? Las mujeres jóvenes y el contrato sexual posfeminista. Debate Feminista, 21(41), 113-135.

Menéndez, M. I. (2006). El zapato de Cenicienta: El cuento de hadas del discurso mediático. Oviuèu: Trabe.

Miedzian, M. (1995). Chicos son, hombres serán. Cómo romper los lazos entre masculinidad y violencia. Madrid: Horas y horas.

Millares, A. (2003). Democracia feminista. Madrid: Cátedra. Colección Feminismos.

Millet, K. (2017). Política sexual. Madrid: Cátedra. Colección Feminismos. $2^{\mathrm{a}}$ ed.

Nussbaum, M. C. (2005). El cultivo de la humanidad. Una defensa clásica de la reforma en la educación liberal. Barcelona: Paidós.

Nussbaum, M. C. (2012a): Crear capacidades. Propuesta para el desarrollo humano. Barcelona: Paidós.

Nussbaum, M. C. (2012b). Las mujeres y el desarrollo humano. Barcelona: Herder.

Nigozi, C. (2017). Querida ljeawele. Como educar en feminismo. Random House.

Osborne, R. (2009). Apuntes sobre la violencia de género. Barcelona: Bellaterra. 
Posada, L. (2012). Sexo, vindicación y pensamiento. Madrid: Huerga y Fierro.

Renau, M. D. (Ed.) (2012). Cómo aprender a amar en la escuela. Madrid: Los libros de la Catarata.

Rodríguez, C. (2011). Género y cultura escolar. Madrid: Morata.

Rodríguez, R. (Ed.) (2015). Sin género de dudas. Logros y desafíos del feminismo hoy. Madrid: Biblioteca Nueva.

Sánchez, M. (Coord.) (2009). Cómo educar en la diversidad afectivo-sexual en los centros escolares. Orientaciones prácticas para la ESO. Madrid: Catarata.

Sánchez, A. e Iglesias, A. (2008). Curriculum oculto en el aula: estereotipos en acción. En R. Cobo (Ed.), Educar en la ciudadanía: perspectivas feministas (pp. 123149). Madrid: Catarata.

San Segundo, T. (2016). A vueltas con la violencia. Una aproximación multidisciplinar a la violencia de género. Madrid: Tecnos.

Sau, V. (2000). Diccionario ideológico feminista. Vol. 1, $2^{\circ}$ ed. Barcelona: Icaria.

Savin-Willians, R. (2009). La nueva adolescencia homosexual. Madrid: Morata.

Simón, E. (2015). ¿Dónde estás feminismo? ¿Cambiaste nuestras vidas? En R. M. Rodríguez (Ed.), Sin género de dudas (pp. 203- 234). Madrid: Biblioteca Nueva.

Subirats, M. y Tomé, A. (2007). Balones fuera: reconstruir los espacios desde la coeducación. Barcelona: Octaedro.

Subirats, M. y Castells, M. (2007). Mujeres y hombres ¿Un amor imposible? Madrid: Alianza.

Subirats, M. (2008). La masculinidad hoy: un género obsoleto. En: Actas del Congreso internacional e interdisciplinar Mundos de Mujeres Women's Worlds. La igualdad no es una utopía. Nuevas fronteras: avances y desafíos. Madrid: Universidad Complutense de Madrid.

Subirats, M. (2016). De los dispositivos selectivos en la educación: el caso del sexismo. Revista de la Asociación de Sociología de la Educación (RASE), 9, 22-36.

Tomé, A. y Rambla, X. (Ed.) (2001). Contra el sexismo. Coeducación y democracia en la escuela. Barcelona: Síntesis.

Valcárcel, A. (2009). Feminismo en el mundo global. Madrid: Cátedra. Colección Feminismos.

Varela, N. (2017). Cansadas: Una reacción feminista frente a la nueva misoginia. Barcelona: Ediciones B.

Varela, J. (2016). Introducción. En J. Varela, P. Parra y A. Val (Eds.), Memorias para hacer camino. Relatos de vida de once mujeres españolas de la generación del 68. Madrid: Morata.

\section{Leyes e Informes}

Ley orgánica 1/2004, del 28 de diciembre, medidas de protección integral contra la violencia de género. BOE-A-2004-21760.

Ley orgánica 3/2007, del 22 de marzo, para la igualdad efectiva de mujeres y hombres. BOE-A-2007-6115. 
Mujeres y hombres en España (2017). Instituto Nacional de Estadística. Ministerio de Sanidad y Servicios Sociales. Ministerio de Sanidad, Servicios Sociales e Igualdad. http://www.ine.es/ss/Satellite?L=es_ES\&c=INEPublicacion_C\&cid=12599248228 $88 \& p=1254735110672 \&$ pagename $=$ ProductosYServicios\%2FPYSLayout $\&$ param $1=$ PYSDetalleGratuitas.

Las cifras de la educación en España. Curso 2014-2015 (ed. 2017). Subdirección General de Estadística y Estudios. Ministerio de Educación, Cultura y Deporte. http://www.mecd.gob.es/servicios-al-ciudadano-mecd/estadisticas/educacion/ indicadores-publicaciones-sintesis/cifras-educacion-espana/2014-15.html.

La evolución de la adolescencia española sobre la igualdad y la prevención de la violencia de género. Delegación del Gobierno para la Violencia de Género. Ministerio de Sanidad, Servicios Sociales e Igualdad (2014). http://www.violenciagenero.msssi. gob.es/violenciaEnCifras/estudios/colecciones/estudio/evolucion2014.htm.

Jóvenes y género. El Estado de la cuestión. Un análisis a partir de fuentes secundarias. Centro Reina Sofía sobre Adolescencia y Juventud. Madrid, 2015. http:// adolescenciayjuventud.org/que-hacemos/monografias-y-estudios/ampliar.php/ Id_contenido/73892/tipo/17/. 